\title{
Reduced Respiratory Control with ADP and Changed Pattern of Respiratory Chain Enzymes as a Result of Selective Deficiency of the Mitochondrial ATP Synthase
}

\author{
JOHANNES A. MAYR, JAN PAUL, PETR PECINA, PETER KURNIK, HOLGER FÖRSTER, \\ ULRIKE FÖTSCHL, WOLFGANG SPERL, AND JOSEF HOUŠTĚK \\ Department of Pediatrics [J.A.M., H.F., U.F., W.S.], General Hospital Salzburg, A-5020 Salzburg, \\ Austria; Department of Bioenergetics [J.P., P.P., J.H.], Institute of Physiology, Academy of Sciences of \\ the Czech Republic, CZ 14220 Prague, Czech Republic; and Department of Pediatrics [P.K.], General \\ Hospital Klagenfurt, A-9020 Klagenfurt, Austria
}

\section{ABSTRACT}

The $\mathrm{F}_{\mathrm{o}} \mathrm{F}_{1}$-ATPase, a multisubunit protein complex of the inner mitochondrial membrane, produces most of the ATP in mammalian cells. Mitochondrial diseases as a result of a dysfunction of ATPase can be caused by mutations in mitochondrial DNA-encoded ATPase subunit a or rarely by an ATPase defect of nuclear origin. Here we present a detailed functional and immunochemical analysis of a new case of selective and generalized ATPase deficiency found in an Austrian patient. The defect manifested with developmental delay, muscle hypotonia, failure to thrive, ptosis, and varying lactic acidemia (up to 12 $\mathrm{mmol} / \mathrm{L}$ ) beginning from the neonatal period. A low-degree dilated cardiomyopathy of the left ventricle developed between the age of 1 and 2 y. A $>90 \%$ decrease in oligomycin-sensitive ATPase activity and an $86 \%$ decrease in the content of the ATPase complex was found in muscle mitochondria. It was associated with a significant decrease of ADP-stimulated respi- ration of succinate (1.5-fold) and respiratory control with ADP (1.7-fold) in permeabilized muscle fibers, and with a slight decrease of the respiratory chain complex I and compensatory increase in the content of complexes III and IV. The same ATPase deficiency without an increase in respiratory chain complexes was found in fibroblasts, suggesting a generalized defect with tissue-specific manifestation. Absence of any mutations in mitochondrial ATP6 and ATP8 genes indicates a nuclear origin of the defect. (Pediatr Res 55: 988-994, 2004)
BN-PAGE, Blue-Native PAGE
DDM, dodecyl maltoside
FCCP, carbonyl cyanide 4-triflouromethoxy-phenylhydrazone mtDNA, mitochondrial DNA
OXPHOS, oxidative phosphorylation

Mitochondrial disorders caused by impairment of mitochondrial oxidative phosphorylation (OXPHOS) affect predominantly tissues with high-energy demands: muscle, brain, and heart. Subunits of OXPHOS complexes are encoded in two separate genomes: nuclear and mitochondrial. A pathogenic mutation in both genomes can cause an OXPHOS defect. Defects in complex V-mitochondrial $\mathrm{F}_{\mathrm{o}} \mathrm{F}_{1^{-}}$ ATPase are less frequent than the defects of the respiratory chain complexes, but they are mostly very severe and can be

Received June 5, 2003; accepted February 4, 2004.

Correspondence: Dr. Josef Houštěk, M.D., Ph.D., Department of Bioenergetics, Institute of Physiology, Academy of Sciences of the Czech Republic, Vídeňská 1083, CZ 142 20 Prague 4, Czech Republic; e-mail: houstek@biomed.cas.cz

This work was supported by bilateral Czech-Austrian Grant KONTAKT 2001-20, Grant Agency of Ministry of Health of the Czech Republic (NE 6533-3), institutional projects (AVOZ5011922, VZ 111100003), and the Jubiläumsfond of the Oesterreichische Nationalbank (no. 8314).

DOI: 10.1203/01.pdr.0000127016.67809.6b caused by mitochondrial DNA (mtDNA) mutations or by mutations in nuclear genes.

Mitochondrial ATPase is a multisubunit complex composed of 16 different subunits (1). Six of these compose the globular $F_{1}$ part, which is responsible for enzymatic catalysis of ATP synthesis or hydrolysis. Ten remaining subunits form the membrane-spanning $\mathrm{F}_{\mathrm{o}}$ part, which performs $\mathrm{H}^{+}$translocation across the inner mitochondrial membrane. Four subunits of $F_{o}$ form stalks that connect $F_{1}$ and $F_{o}$ parts. Only two subunits from $\mathrm{F}_{\mathrm{o}}$ part are encoded by mitochondrial genome: subunits a and A6L (subunits 6 and 8) (2). All of the other 14 subunits of the ATPase are encoded by the nuclear genes.

Specific defects in mitochondrial ATPase are caused mainly by mtDNA mutations that affect subunit a; no mutations in subunit A6L have been described so far. The most frequent mutation in subunit a is T8993G mutation (3-7) or T8993C mutation (8), which changes Leu ${ }^{156}$ to Arg or Pro 
and manifests as a NARP syndrome (neurogenic muscle weakness, ataxia, retinitis pigmentosa) $(4,5)$, or maternally inherited Leigh syndrome (severe and fatal encephalopathy) $(3,6,7)$. The 8993 mutations impair the $\mathrm{H}^{+}$channel, resulting in decreased ATP production $(4,9,10)$. Several other, less frequent mtDNA mutations of subunit a at positions 9176 and 8851 were also described (for review, see Ref. (11)), resulting in a similar predominant lesion in the brain, particularly in striatum (familiar bilateral striatal necrosis).

Defects of mitochondrial ATPase caused by nuclear genome mutations seem to be rare. A case of ATPase deficiency of possible nonmitochondrial origin was found in 1992 in Sweden by Holme et al. (12) in a child with 3-methylglutaconic aciduria and severe lactic acidosis. Muscle mitochondria showed extremely low ATPase activity and also a low, tightly coupled respiration rate. Ultrastructural abnormalities of mitochondria were also detected. However, no mutation was found in mtDNA genes encoding ATPase subunits.

Nuclear origin of selective ATP synthase deficiency was for the first time demonstrated in 1999 (13) in a new type of fatal mitochondrial disorder. The child with severe lactic acidosis, cardiomegaly, and hepatomegaly died $2 \mathrm{~d}$ after birth. The ATPase activity in muscle was $31 \%$ to $34 \%$ of control; electrophoretic and Western blot analysis showed a selective, $70 \%$ decrease of the ATPase complex that had normal size and subunit composition, whereas the levels of cytochrome $c$ oxidase, citrate synthase, and pyruvate dehydrogenase were normal. The same defect was present in fibroblasts in which the ATP synthesis was only $30 \%$ of control. Pulse-chase labeling showed decreased biosynthesis of assembled ATPase but increased incorporation of ${ }^{35} \mathrm{~S}$-methionine into the immunoprecipitated $\beta$ subunit, which had a very short half-life. Cybrid cell lines made of patient fibroblasts and 143B.TK $\rho^{0}$ cells fully complemented the ATPase defect as well as the decreased ATPase biosynthesis. It was concluded that this selective ATPase deficiency is of nuclear origin and is caused by impaired biogenesis of the enzyme complex (13). The same ATPase deficiency was found later in the patient's sister.

The third case of similar selective ATPase defect was described in Belgium in 2001 in a child who had severe lactic acidosis, hepatomegaly, and cardiac failure and died $3 \mathrm{~d}$ after birth (14). The ATPase deficiency was found in heart, skeletal muscle, and skin fibroblasts using catalytic activity measurements and activity staining of OXPHOS enzymes resolved by Blue-Native electrophoresis.

Here we present a detailed functional and immunochemical analysis of a new case of selective ATPase defect found in an Austrian patient indicating that a $90 \%$ decrease of the ATPase content in muscle results in a significant decrease of ADPstimulated respiration and in a compensatory increase in the content of respiratory chain complexes III and IV. The same ATPase deficiency without increase in respiratory chain complexes was found in fibroblasts, suggesting tissue-specific manifestation of the defect.

\section{METHODS}

This study was carried out in accordance with the Declaration of Helsinki of the World Medical Association and was approved by the Committees of Medical Ethics at all collaborating institutions. Informed consent was obtained from parents.

Case report. A girl was born from the second uncomplicated pregnancy (first pregnancy artificially terminated) of an 18-yold mother (with mild mitral valve insufficiency) and a healthy father. The birth was uneventful and spontaneous in the 36th week of gestation with Apgar score of 7-8-9, birth weight of $1800 \mathrm{~g}$, length of $42.5 \mathrm{~cm}$, and head circumference of $29.5 \mathrm{~cm}$ (all parameters below the third percentile for the gestational age-intrauterine hypotrophy). The newborn child was hypotonic, with low spontaneous activity, irregular breathing, and peripheral cyanosis. After upper respiratory tract cleaning, manual stimulation, and short oxygen administration, the breathing pattern normalized. During the first $3 \mathrm{wk}$ of life, her blood lactate level was elevated (max. $5.9 \mathrm{mmol} / \mathrm{L}$ ). At the age of $3 \mathrm{mo}$, the patient came to the hospital because of muscle hypotonia, diarrhea, and insufficient drinking. Ptosis of the right eyelid developed, and slight asymmetry of the face was noted. The girl had a metabolic acidosis $(\mathrm{pH} 7.26$, base excess $10.8, \mathrm{HCO}_{3}$ 15.2, $\mathrm{PCO}_{2} 35.3$ ), and her blood lactate was elevated to $12.4 \mathrm{mmol} / \mathrm{L}$ but was stabilized by bicarbonate $\left(\mathrm{NaHCO}_{3} 4.2 \%\right.$ solution) administration. A magnetic resonance imaging scan of her brain at the ages of 4 mo and $2 y$ showed no abnormalities. A muscle biopsy was taken at the age of 5 mo to investigate the mitochondrial energy metabolism. Histologically, there were only minor myopathologic abnormalities detected with an indication for a developmental delay because of a slight utrophin up-regulation. No ragged red fibers or cytochrome $c$ oxidase-negative fibers were detectable.

At the age of $7 \mathrm{mo}$, body weight was $4870 \mathrm{~g}$, length was 62.5 $\mathrm{cm}$ (below the third percentile), muscle strength was still reduced, the child began rolling over, and the eyelid ptosis was ameliorated. At the age of $2 \mathrm{y}$, the motor development is still retarded, the child is hypotonic, but she is able to stand without help. Body weight is $6.8 \mathrm{~kg}$ (below the third percentile). Between the age of 1 and $2 \mathrm{y}$, the patient developed a lowdegree dilated cardiomyopathy of the left ventricle (end diastolic diameter $30 \mathrm{~mm}$ ), which at the moment is well compensated. The girl is frequently hospitalized because of feeding problems and/or vomiting. Lactate level remained increased (2-6 mmol/L).

Importantly, the parents of the child are second-degree cousins, the sister of the mother died of sudden infant death at the age of $3 \mathrm{mo}$, a grand-aunt of the mother is deaf, and the sibling of the father died at the age of 3 mo of unknown cause.

Cell culture and preparation of mitochondria from skin fibroblasts. Fibroblast cultures were established from skin biopsies, and cells were grown in Dulbecco's modified Eagle's medium (Sigma Chemical Co., St. Louis, MO, U.S.A.) containing 10\% FCS (Greiner, Frickenhausen, Germany), gentamicin $40 \mu \mathrm{g} / \mathrm{mL}$ or penicillin $(100 \mathrm{IE} / \mathrm{mL})$, and streptomycin $(100 \mu \mathrm{g} / \mathrm{mL})$ at $37^{\circ} \mathrm{C}$ in $5 \% \mathrm{CO}_{2}$ in air. Confluent cells were harvested by trypsin release and centrifugation (10 min, $250 \times$ 
g). After washing twice with PBS $(8 \mathrm{~g} / \mathrm{L} \mathrm{NaCl}, 0.2 \mathrm{~g} / \mathrm{L} \mathrm{KCl}$, $1.15 \mathrm{~g} / \mathrm{L} \mathrm{Na} \mathrm{NPO}_{4}, 0.20 \mathrm{~g} / \mathrm{L} \mathrm{KH}_{2} \mathrm{PO}_{4}$ ), mitochondria were isolated according to Bentlage et al. (15).

Preparation of postnuclear supernatant from muscle. Muscle specimens $(15-25 \mathrm{mg})$ were minced with a pair of scissors followed by homogenization with a tissue disintegrator (Ultraturrax; IKA, Staufen, Germany) in extraction buffer $(250 \mathrm{mM}$ sucrose, $40 \mathrm{mM} \mathrm{KCl}, 20 \mathrm{mM}$ Tris/HCl, pH 7.62, 2 mM EGTA) and final homogenization with a motor-driven Teflon-glass homogenizer (Potter S; Braun, Melsungen, Gemany). The homogenate was centrifuged at $600 \times \mathrm{g}$ for $10 \mathrm{~min}$ at $4^{\circ} \mathrm{C}$. The supernatant was taken for measuring the mitochondrial enzymes (16).

Measurement of enzymes of the mitochondrial energy metabolism. The following enzyme activities were determined accordingly: citrate synthase (17), complex I and I+III (18), complex II and II+III (19), complex III (18), and complex IV (20), with modifications described (16). Oligomycin-sensitive ATPase of complex V was determined using buffer conditions described by Rustin et al. (18) by sonifying the whole reaction mixture for $10 \mathrm{~s}$ with an ultrasonifier (Bio cell disruptor 250; Branson, Danbury, CT, U.S.A.) at the lowest energy output. All spectrophotometric measurements (Uvicon 922; Kontron, Milan, Italy) were performed at $37^{\circ} \mathrm{C}$. Protein content was measured with the BCA assay (Pierce, Rockford, IL, U.S.A.) (21).

Respirometric analysis of native muscle fibers and cultured fibroblasts. Saponin-skinned muscle fibers were prepared as described earlier (22). Using a high-resolution respirometer (Oxygraph2k; Oroboros Instruments, Innsbruck, Austria), 5-8 $\mathrm{mg}$ of skinned fibers were analyzed in $1.1 \mathrm{~mL}$ of buffer containing $110 \mathrm{mM}$ sucrose, $60 \mathrm{mM} \mathrm{K}$-lactobionate, $20 \mathrm{mM}$ taurine, $20 \mathrm{mM}$ HEPES, $10 \mathrm{mM} \mathrm{KH} \mathrm{PO}_{4}, 3 \mathrm{mM} \mathrm{MgCl}{ }_{2}, 0.5$ mM EGTA, and $0.1 \%$ BSA adjusted to $\mathrm{pH} 7.1$ with $\mathrm{NaOH}$ (23). Oxygen consumption of fibroblasts was determined as described previously (24) using freshly harvested fibroblasts resuspended in a $\mathrm{KCl}$ medium $(80 \mathrm{mM} \mathrm{KCl}, 10 \mathrm{mM}$ Tris-HCl, $3 \mathrm{mM} \mathrm{MgCl} 2,1 \mathrm{mM}$ EDTA, $5 \mathrm{mM}$ potassium phosphate, $\mathrm{pH}$ 7.4) at a protein concentration of $1 \mathrm{mg} / \mathrm{mL}$. Cells were permeabilized by $0.05 \mathrm{mg}$ digitonin $/ \mathrm{mg}$ protein. Various respiratory substrates and inhibitors were used as indicated. Oxygen consumption of muscle fibers and fibroblasts was expressed in $\mathrm{nmol} \mathrm{O}_{2} \cdot \min ^{-1} \cdot \mathrm{mg}$ fiber ${ }^{-1}$ and in pmol $\mathrm{O}_{2} \cdot \mathrm{s}^{-1} \cdot \mathrm{mg}$ protein $^{-1}$, respectively.

Sequence analysis of mitochondrial DNA. The mitochondrial DNA from position 8301 to 9272, including the genes ATP6 and ATP8, was analyzed by automatic sequencing of PCR products.

Blue-Native PAGE. Blue-Native PAGE (BN-PAGE) (25) was used for separation of samples prepared by solubilization of sedimented mitochondrial membranes $(15,000 \times g, 10 \mathrm{~min})$ from muscle and fibroblast with dodecyl maltoside (DDM; $10 \% \mathrm{DDM}$ at a protein concentration of $2 \mathrm{mg} / \mathrm{mL}$ ). Electrophoresis was carried out on a $6-15 \%$ linear gradient of polyacrylamide. Sample protein was measured by method of Bradford before addition of 5\% Serva Blue G. For analysis, aliquots of 5-10 $\mu \mathrm{g}$ protein/slot were used.
SDS PAGE. SDS-Tricine electrophoresis (26) on 10\% polyacrylamide slab gels (Mini Protean; BioRad, Hercules, CA, U.S.A.) was used for analysis of individual OXPHOS subunits. The samples of mitochondria were boiled for $3 \mathrm{~min}$ in sample lysis buffer (2\% mercaptoethanol, 4\% SDS, $10 \mathrm{mM}$ Tris- $\mathrm{HCl}$, $10 \%$ glycerol), and the same aliquots of control and patient samples of mitochondria ( $5 \mu \mathrm{g}$ protein/slot) were loaded.

Western blotting and computer image analysis. Proteins from the slab gels were blotted onto nitrocellulose membrane (Hybond C-extra; Amersham, Biosciences, Upsala, Sweden) by semidry electrotransfer at $0.7 \mathrm{~mA} / \mathrm{cm}^{2}$ for $1 \mathrm{~h}$, and the membrane was blocked in PBS with $0.2 \%$ Tween 20 (PBST). Membranes from SDS-PAGE were cut according to MW markers (Amersham) into parts that contained desired proteins; membranes from native electrophoresis were used as a whole. Membranes were incubated for $2.5 \mathrm{~h}$ with primary antibodies diluted in PBST containing 2\% BSA (PBSTA), followed by incubation for $1.5 \mathrm{~h}$ with peroxidase-labeled goat anti-mouse IgG (A8924; Sigma Chemical Co.) diluted 1:1000 in PBSTA or with peroxidase-labeled goat anti-rabbit IgG (A9169; Sigma Chemical Co.). The chemiluminescence reaction using ECL kit (Amersham) was detected on LAS 1000 (Fujifilm, Stamford, CT, U.S.A.), and the signal was quantified using Aida 2.11 Image Analyser software.

Antibodies. Immunodetection was performed with subunitspecific mouse MAb obtained from Molecular Probes: antiNADH39 subunit of complex I (1:250), anti-SDH70 subunit of complex II (1:2000), anti-Core1 subunit of complex III (1:1000), anti-COX4 subunit of complex IV (1:1666), and anti- $\mathrm{F}_{\mathrm{o}}-\mathrm{OSCP}$ subunit of ATPase (1:250). In addition, rabbit polyclonal antibody anti- $\mathrm{F}_{\mathrm{o}}-\mathrm{c}$ subunit of ATPase (1:900, see Ref. (10)) and monoclonal anti-ATPase $F_{1}-\alpha$ subunit antibody (1:200,000, obtained from Prof. C. Godinot, Universite Claud Bernard de Lyon I, Lyon, France) were used.

\section{RESULTS}

Activities of OXPHOS complexes. Table 1 shows activities of OXPHOS complexes measured by spectrophotometric methods in muscle and fibroblasts of the patient. Analysis of muscle homogenate showed pronounced, almost 20-fold decrease of oligomycin-sensitive ATPase activity. In contrast, specific activities of respiratory chain complexes were in the upper control range (complex II, III, and IV) or showed only a small decrease (complex I). A similar profile of OXPHOS activities was found in fibroblasts, where specific activity of ATPase was 4-fold decreased and activities of complexes I, II, III, and IV were in control range. Relative to complex IV or citrate synthase, the ATPase was 27- to 31-fold decreased in muscle and 3.5- to 4.2-fold in fibroblasts, indicating tissuespecific differences in the extent of the ATPase defect. It is interesting that the complex I/citrate synthase as well as complex I/complex IV and complex I/complex III ratios (not shown) were $\sim 2$-fold decreased in muscle but unchanged in fibroblasts.

Results of polarographic measurement of respiration in patient and control muscle fibers permeabilized with saponin are summarized in Table 2. ADP-stimulated respiration with pyru- 
Table 1. Activites of respiratory chain enzymes and oligomycin-sensitive ATPase in muscle and fibroblasts

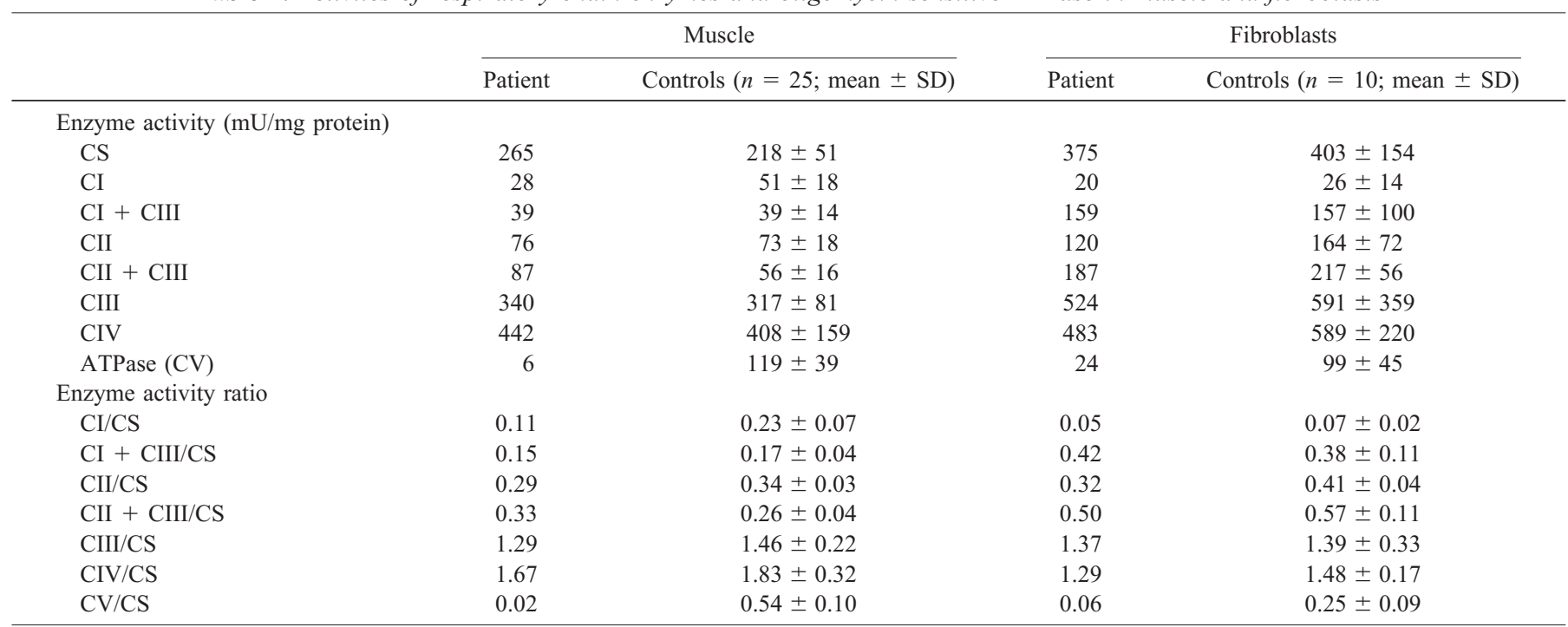

CS, citrate synthase; CI, complex I; CII, complex II; CIII, complex III; CIV, complex IV; CV, complex V

vate + malate or succinate + rotenone was decreased in the patient 2.3 -fold and 1.5 -fold, respectively, whereas the respiration with $\mathrm{N}, \mathrm{N}, \mathrm{N}^{\prime}, \mathrm{N}^{\prime}$-tetramethyl-1,4-phenylendiamid + ascorbate in the presence of carbonyl cyanide 4-triflouromethoxy-phenylhydrazone (FCCP), indicative of the respiratory capacity, was normal. Respiratory control with succinate and ADP thus was 1.7-fold lower in patient muscle. Similar results were obtained in digitonin-permeabilized fibroblasts (Fig. 1). We found a 1.4-fold decrease in ADP-stimulated respiration with succinate as a substrate in patient cells, where the respiration in the presence of FCCP was equal to control. The ADP-stimulated respiration in patient fibroblasts was completely inhibited by oligomycin, and FCCP-stimulated respiration was blocked by antimycin A. Respiratory control with ADP was 1.7-fold lower in patient cells (2.4 in patient versus 4.1 in the control cells), indicating a pronounced decrease in ATP synthesis coupled to substrate oxidation in mitochondria

Table 2. Polarographic analysis of saponin-permeabilized muscle fibers

\begin{tabular}{|c|c|c|}
\hline $\begin{array}{c}\text { Substrate } \\
\left(\text { nmol O}_{2} \cdot \min ^{-1} \cdot \mathrm{mg} \mathrm{fiber}^{-1}\right)\end{array}$ & Patient & $\begin{array}{c}\text { Controls } \\
(n=15 ; \\
\text { mean } \pm \mathrm{SD})\end{array}$ \\
\hline Pyruvate + malate + ADP & 0.68 & $1.58 \pm 0.32$ \\
\hline Succinate + ADP & 1.11 & $1.66 \pm 0.42$ \\
\hline Succinate + ADP + atractylate & 0.54 & $0.42 \pm 0.11$ \\
\hline $\mathrm{TMPD}+$ ascorbate $+\mathrm{FCCP}$ & 2.75 & $3.18 \pm 0.98$ \\
\hline Respiratory control with succinate & 2.1 & $3.90 \pm 1.10$ \\
\hline
\end{tabular}

The polarographic analysis (see "Methods") was started by addition of 10 $\mathrm{mM}$ pyruvate and $2 \mathrm{mM}$ malate in the presence of $2 \mathrm{mM}$ ADP, followed by inhibition with $5 \mu \mathrm{M}$ rotenone. Then $10 \mathrm{mM}$ succinate was added, and ADP dependence was measured by the addition of $50 \mu \mathrm{M}$ atractylate followed by inhibition with $4 \mu \mathrm{M}$ antimycin A. Finally, cytochrome $c$ oxidase was determined with $0.5 \mathrm{mM}$ TMPD $+2 \mathrm{mM}$ ascorbate in the presence of $0.5 \mu \mathrm{M}$ FCCP followed by inhibition using $1 \mathrm{mM} \mathrm{KCN}$. Inhibitor-sensitive activities were calculated. The chamber was aerated when the oxygen concentration was $<50 \%$ of saturation. of patient cells. Despite the pronounced ATPase defect, a significant ATP synthesis seems to be present in both muscle and fibroblasts.

Changes in the content of mitochondrial ATPase and respiratory chain enzymes. The specific content of OXPHOS

\section{(A) Control fibroblasts}

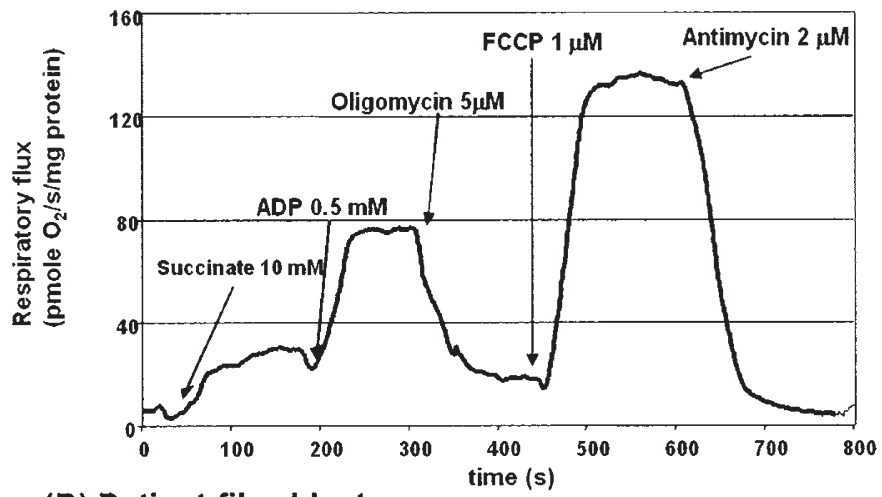

(B) Patient fibroblasts



Figure 1. Respirometric analysis of patient and control fibroblasts. Polarographic measurements on control $(A)$ and patient $(B)$ fibroblasts were carried out in a $\mathrm{KCl}$ buffer using $1 \mathrm{mg}$ protein $/ \mathrm{mL}$; additions of substrates or inhibitors are indicated. The respiration rate is expressed in pmol oxygen $\cdot \mathrm{s}^{-1} \cdot \mathrm{mg}$ protein $^{-1}$. 


\section{Muscle mitochondria}
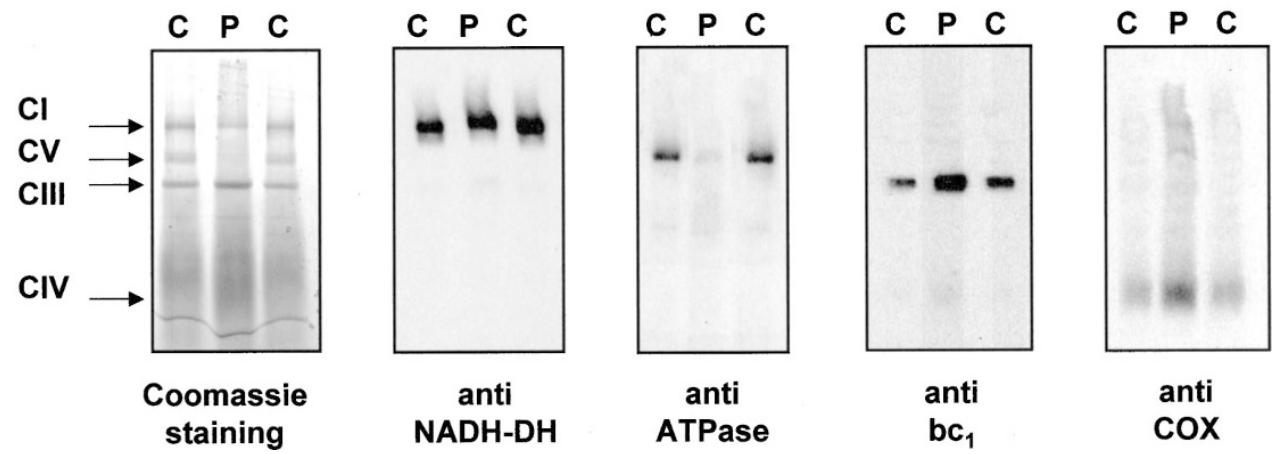

Figure 2. Electrophoretic analysis of solubilized muscle mitochondria. Isolated mitochondria from muscle were solubilized by addition of $10 \%$ DDM at a protein concentration of $2 \mathrm{mg} / \mathrm{mL} ; 10-\mu \mathrm{g}$ aliquots of solubilized proteins were loaded. The gel was either stained with Coomassie Blue R or analyzed by Western blotting using MAb against a 39-kD subunit of complex I (NADH-DH), $\alpha$ subunit of ATPase (ATPase), Core 1 subunit of complex III (bc ${ }_{1}$ ), and COX4 subunit of complex IV (COX). Arrows show the mobility of individual OXPHOS complexes. C, control; P, patient.

complexes was determined in DDM-solubilized proteins prepared from isolated mitochondria of both muscle and cultured fibroblasts. Samples were analyzed by BN-PAGE, and proteins were detected by staining and/or Western blotting. Figure 2 shows the specific content of ATPase and respiratory chain complexes I, III, and IV detected by Coomassie Blue staining in muscle mitochondria. There was an apparent selective decrease in the content of ATPase complex, whereas the staining of complexes I, III, and IV was comparable in patient and control. Detailed Western blot analysis using subunit-specific MAb confirmed the specific quantitative defect of the ATPase complex, which had normal mobility indicating unchanged size and subunit composition of the assembled ATPase complex (Fig. 2). Below the ATPase complex, the antibody to $F_{1}-\alpha$ subunit showed a faint band at $\sim 390 \mathrm{kD}$, which, relative to assembled ATPase, was stronger in patient muscle, indicating possible accumulation of $F_{1}-\alpha$ subunit-containing material, corresponding to the size of $F_{1}$.

Western blots further showed unchanged content of complex I and increased content of complexes III and IV (Fig. 2). On the basis of quantification of immunoblotting signals (Table 3)

Table 3. Electrophoretic quantification of DDM-solubilized respiratory chain enzymes and ATPase from muscle and fibroblasts

\begin{tabular}{cccc}
\hline \multicolumn{2}{c}{ Muscle } & Fibroblasts \\
\cline { 2 - 3 } & Staining & WB & WB* \\
\hline
\end{tabular}

$\begin{array}{lccc}\begin{array}{l}\text { Specific content in } \\ \text { \% of control }\end{array} & & & \\ \text { CI } & 53.8 & 112.4 & 68.7 \\ \text { CIII } & 138.3 & 311.9 & 95.2 \\ \text { CIV } & 196.5 & 204.3 & 87.1 \\ \text { CV } & 8 & 14 & 5 \\ \text { Relative ratio } & & & \\ \text { CV/CI } & 0.15 & 0.12 & 0.07 \\ \text { CV/CIII } & 0.06 & 0.05 & 0.05 \\ \text { CV/CIV } & 0.04 & 0.07 & 0.06\end{array}$

Coomassie Blue staining of BN-PAGE gels and chemiluminescence reaction using ECL kit of the Western blots as shown in Figs. 2 and 3 were scanned on a LAS 1000 (Fuji, Japan), and the signal was quantified using Aida 2.11 Image Analyser software.

* Mean value of two experiments. using a fluoroimager, the specific content of ATPase in patient was $14 \%$ of control. The decrease in the patient of ATPase relative to complex I was $\sim 8.3$-fold, and relative to complexes III and IV, it was $\sim 20$ - and 14-fold, respectively. This indicates that specific ATPase defect may be connected with increased content of respiratory chain complexes III and IV. The quantification of Coomassie Blue staining (Table 3) gave a similar picture indicating approximately 12 -fold decrease of complex $\mathrm{V}$ and increased content of complexes III and IV.

Western blot analysis further showed that the selective ATPase defect was fully expressed in patient fibroblasts (Fig. $3 A$ ), where it also revealed an $\mathrm{F}_{1}-\alpha$ subunit-containing a faint band at $\sim 390 \mathrm{kD}$. The quantification of BN-PAGE Western blot data from two experiments revealed a 13- to 20-fold decrease of ATPase content relative to the content of complexes I, III, and IV. This was further confirmed by SDSPAGE Western blot analysis of $F_{1}$-ATPase subunits $\left(F_{1}-\alpha\right.$, $\mathrm{F}_{\mathrm{o}}-\mathrm{OSCP}, \mathrm{F}_{\mathrm{o}}-\mathrm{c}$ ) in patient fibroblast mitochondria, which showed pronounced decrease of all ATPase subunits tested (Fig. 3B). As also shown by BN-PAGE, there was a slight decrease of complex I but no apparent change in complexes III and IV content in patient fibroblasts (Table 3 ). This complies with the above results indicating that the ATPase deficiency has generalized character and that some compensatory changes in biosynthesis of respiratory chain enzymes may occur.

\section{DISCUSSION}

In this report, we describe a patient who had a quantitative defect of the mitochondrial $\mathrm{F}_{\mathrm{o}} \mathrm{F}_{1}$-ATP synthase and presented clinically with lactic acidosis and developmental delay from the neonatal period. The clinical course was mild, especially with respect to the key function of the ATPase in the mitochondrial energy metabolism. The intermediate clinical presentation also corresponds with the biochemical results obtained from respirometric investigations of native muscle fibers and fibroblasts, which show significant remaining mitochondrial ATP production (apparent as oligomycin- or atractylosidesensitive respiration). This finding is somewhat surprising in light of severe and generalized reduction of the enzymatic 
Fibroblast mitochondria

A

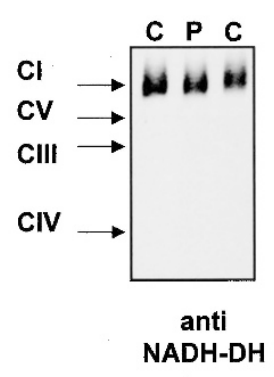

BN-PAGE
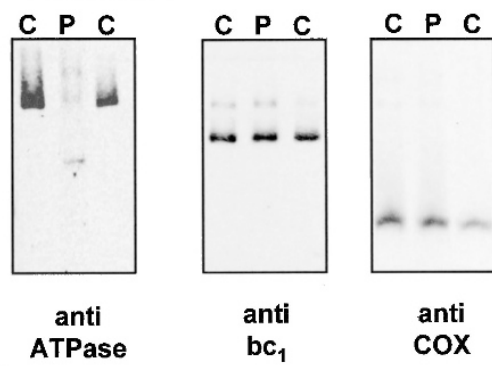

B

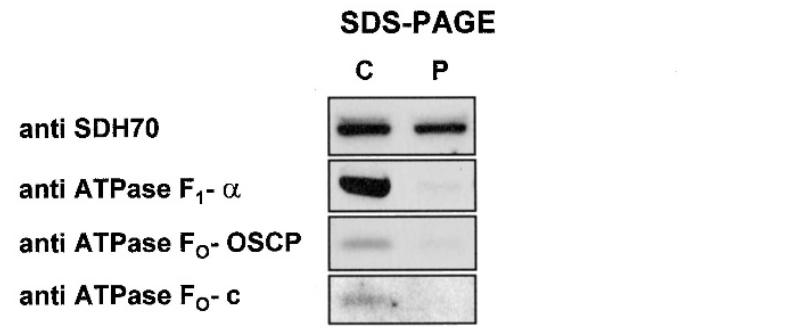

Figure 3. Electrophoretic analysis of mitochondria from cultured fibroblasts. (A) Mitochondria prepared from cultured fibroblasts were solubilized by addition of $10 \% \mathrm{DDM}$ at a protein concentration of $2 \mathrm{mg} / \mathrm{mL} ; 15 \mu \mathrm{g}$ of solubilized protein was loaded on $\mathrm{BN}$ gel. This gel was analyzed by Western blotting as in Fig. 2. Arrows show the mobility of individual OXPHOS complexes. (B) Proteins of mitochondria $(5 \mu \mathrm{g})$ from cultured fibroblasts were separated on SDS-PAGE and analyzed by Western blotting using antibody against a 70-kD subunit of succinate dehydrogenase (SDH70) and antibodies against ATPase subunits $\mathrm{F}_{1}-\alpha, \mathrm{F}_{\mathrm{o}}-\mathrm{OSCP}$ and $\mathrm{F}_{\mathrm{o}}-\mathrm{c}$. $\mathrm{C}$, control; $\mathrm{P}$, patient.

ATPase activity as well as the amount of native ATPase protein complex. Conversely, it is known from inhibitor titration studies $(27,28)$ that individual OXPHOS enzymes of the mitochondrial energy metabolism can be inhibited to a certain extent without noticeable reduction of the mitochondrial coupled respiration rate. These threshold effects are different for individual OXPHOS complexes and thresholds also display tissue specificity. An especially high threshold was found for ATPase in muscle tissue indicating that $10 \%$ of normal activity of the enzyme is sufficient for $>50 \%$ functionality of the whole respiratory chain. This high threshold effect seems to be reflected by the results obtained in our patient. The high ATPase threshold is likely to rescue the energy supply to some extent; however, it might differ in cells and tissues with different genetic background. From the three earlier reported patients with decreased ATPase and absence of mitochondrial mutations, two died within the first days of life $(13,14)$ and one survived for several years (12).

Similar to the previous two reported patients who lacked mutations of the mitochondrial genes ATP6 and ATP8 $(12,13)$, a clear reduction of the hydrolytic activity of mitochondrial ATPase (oligomycin sensitive) was found in investigated tissues. This biochemical parameter clearly indicates a quantitative defect of the whole complex. Biochemical measurements of the ATPase activity, which can be performed with isolated mitochondria but also with crude postnuclear supernatant from muscle, are apparently useful and sufficient to identify this defect. We suggest that ATPase be determined as a standard parameter in patients who have lactic acidosis and are suspected of having a mitochondrial disorder. The ATPase activity was diminished in muscle and fibroblasts; however, in muscle, a tissue with high energy demand, additional differences in respiratory chain enzymes can be seen. In muscle, there is obviously a relative increase in the enzyme activity of respiratory complexes III and IV compared with complex I that was slightly below the normal range. Possibly, complex I, the largest of the respiratory chain complexes and one of the sites of oxygen radicals production, is more vulnerable to their increase found in mitochondrial disorders (29). The data of the enzymatic analysis are also supported by the quantitative expression of the native protein complexes as seen in BN-PAGE and Western blot analysis. Also, here, a clear increase of the complexes III and IV content relative to complex I was found. An up-regulated function of the respiratory chain may help ATPase-defective cells to oxidize the reduced redox equivalents $\mathrm{NADH}$ and $\mathrm{FADH}_{2}$ that accumulate during glycolysis and mitochondrial oxidation of pyruvate and fatty acids. This would be especially effective when the rate of uncoupling is increased. Actually, a decreased respiratory coefficient was found in the respirometric analysis of permeabilized muscle fibers and fibroblasts. This might explain the relatively normal lactate level found during well-balanced periods in our patient.

Deficiency of the $\mathrm{F}_{\mathrm{o}} \mathrm{F}_{1}$-ATP synthase could result from a defect in 1 of the 14 nuclear-encoded or 2 mtDNA-encoded subunits. Structural protein defects of the subunit a, which is encoded by the mitochondrial gene ATP 6 , have been shown to result in incomplete assembly of the complex V holoenzyme. This is known from studies in tissues and cultured cells with the mutation T8993G $(10,30)$, associated with NARP disease but also from rho ${ }^{0}$ cells, which lack mitochondrial DNA (31) as well as cells with inhibited mitochondrial protein synthesis (32), where increased content of unassembled or released $F_{1}$ of $390 \mathrm{kD}$ and accumulation of atypical ATPase subcomplex of $460 \mathrm{kD}$ was found $(10,30)$. In the case of our patient, as detected by BN-PAGE and Western blots of solubilized OXPHOS complexes, possibly some amount of $F_{1}$-like intermediate could be present.

Similar to the previously reported patient with ATPase deficiency of nuclear origin, no mutations could be found in mtDNA genes encoding subunits ATP6 and A6L in the present case, and the ATPase deficiency seems to be associated with an early step in the biogenesis of the ATPase enzyme complex (13). Of particular interest are the $\mathrm{F}_{1}$-specific assembly factors. Up to now, three factors were described in yeast-ATP11, ATP12 (33), and FMC1 (34) - that are necessary for correct incorporation of $\alpha$ and $\beta$ subunits into the $F_{1}$ catalytic part of the ATPase complex. Recently, the human homologues of the first two were found (35), and other specific assembly proteins may be found in the future. Further studies will be required to elucidate the pathogenic mechanism of this disease, which may be caused by a lack or dysfunction of some of the nuclear-encoded ATPase subunits or the factors essential for ATPase assembly.

\section{REFERENCES}

1. Walker JE, Collinson IR 1994 The role of the stalk in the coupling mechanism of F1F0-ATPases. FEBS Lett 346:39-43 
2. Anderson S, Bankier AT, Barrell BG, de Bruijn MHL, Coulson AR, Drouin J, Eperon IC, Nierlich DP, Roe BA, Sanger F, Schreier PH, Smith AJH, Staden R, Young IG 1981 Sequence and organization of the human mitochondrial genome. Nature 290:457-465

3. Tatuch Y, Pagon RA, Vlcek B, Roberts R, Korson M, Robinson BH 1994 The 8993mtDNA mutation: heteroplasmy and clinical presentation in three families. Eur J Hum Genet 2:35-43

4. Holt IJ, Harding AE, Petty RKH, Morgan-Hughes JA 1990 A new mitochondrial disease associated with mitochondrial DNA heteroplasmy. Am J Hum Genet 46:428-433

5. Puddu P, Barboni P, Mantovani V, Montagna P, Cerullo A, Bragliani M, Molinotti C Caramazza R 1993 Retinitis pigmentosa, ataxia, and mental retardation associated with mitochondrial DNA mutation in an Italian family. Br J Ophthalmol 77:84-88

6. Shoffner JM, Fernhoff PM, Krawiecki NS, Caplan DB, Holt PJ, Koontz DA, Takei Y, Newman NJ, Ortiz RG, Polak M 1992 Subacute necrotizing encephalopathy: oxidative phosphorylation defects and the ATPase 6 point mutation. Neurology 42:21682174

7. Ciafaloni E, Santorelli FM, Shanske S, Deonna T, Roulet E, Janzer C, Pescia G, DiMauro S 1993 Maternally inherited Leigh syndrome. J Pediatr 122:419-422

8. de Vries DD, van Engelen BG, Gabreels FJ, Ruitenbeek W, van Oost BA 1993 A second missense mutation in the mitochondrial ATPase 6 gene in Leigh's syndrome. Ann Neurol 34:410-412

9. Tatuch Y, Robinson BH 1993 The mitochondrial DNA mutation at 8993 associated with NARP slows the rate of ATP synthesis in isolated lymphoblast mitochondria. Biochem Biophys Res Commun 192:124-128

10. Houstek J, Klement P, Hermanska J, Houstkova H, Hansikova H, van den Bogert C, Zeman J 1995 Altered properties of mitochondrial ATP-synthase in patients with a T $\rightarrow$ G mutation in the ATPase 6 (subunit a) gene at position 8993 of mtDNA. Biochim Biophys Acta 1271:349-357

11. Schon EA, Santra S, Pallotti F, Girvin ME 2001 Pathogenesis of primary defects in mitochondrial ATP synthesis. Semin Cell Dev Biol 12:441-448

12. Holme E, Greter J, Jacobson CE, Larsson NG, Lindstedt S, Nilsson KO, Oldfors A, Tulinius M 1992 Mitochondrial ATP-synthase deficiency in a child with 3-methylglutaconic aciduria. Pediatr Res 32:731-735

13. Houstek J, Klement P, Floryk D, Antonicka H, Hermanska J, Kalous M, Hansikova H, Houst'kova H, Chowdhury SK, Rosipal T, Kmoch S, Stratilova L, Zeman J 1999 A novel deficiency of mitochondrial ATPase of nuclear origin. Hum Mol Genet 8:1967-1974

14. Van Coster R, Smet J, Eyskens F 2001 Severe complex V deficiency with fata outcome in neonatal period. In: Besley GTN (ed) SSIEM Kluwer Academic Publishers, Prague, p 83

15. Bentlage HA, Wendel U, Schagger H, ter Laak HJ, Janssen AJ, Trijbels JM 1996 Lethal infantile mitochondrial disease with isolated complex I deficiency in fibroblasts but with combined complex I and IV deficiencies in muscle. Neurology 47:243-248

16. Berger A, Mayr JA, Meierhofer D, Fotschl U, Bittner R, Budka H, Grethen C, Huemer M, Kofler B, Sperl W 2003 Severe depletion of mitochondrial DNA in spinal muscular atrophy. Acta Neuropathol (Berl) 105:245-251

17. Srere PA 1969 Citrate synthase. Methods Enzymol 13:3-26

18. Rustin P, Chretien D, Bourgeron T, Gerard B, Rotig A, Saudubray JM, Munnich A 1994 Biochemical and molecular investigations in respiratory chain deficiencies. Clin Chim Acta 228:35-51

19. Birch-Machin MA, Briggs HL, Saborido AA, Bindoff LA, Turnbull DM 1994 An evaluation of the measurement of the activities of complexes I-IV in the respi- ratory chain of human skeletal muscle mitochondria. Biochem Med Metab Biol $51: 35-42$

20. Trounce IA, Kim YL, Jun AS, Wallace DC 1996 Assessment of mitochondrial oxidative phosphorylation in patient muscle biopsies, lymphoblasts, and transmitochondrial cell lines. Methods Enzymol 264:484-509

21. Smith PK, Krohn RI, Hermanson GT, Mallia AK, Gartner FH, Provenzano MD, Fujimoto EK, Goeke NM, Olson BJ, Klenk DC 1985 Measurement of protein using bicinchoninic acid. Anal Biochem 150:76-85

22. Sperl W, Skladal D, Gnaiger E, Wyss M, Mayr U, Hager J, Gellerich FN 1997 High resolution respirometry of permeabilized skeletal muscle fibers in the diagnosis of neuromuscular disorders. Mol Cell Biochem 174:71-78

23. Gnaiger E, Kuznetsov A, Schneeberger S, Seiler R, Brandacher G, Steurer W, Margreiter R 2000 Mitochondria in cold. In: Heldmaier G, Klingenspor M (eds) Life in the Cold. Springer, Heidelberg, pp 431-442

24. Chowdhury SK, Drahota Z, Floryk D, Calda P, Houstek J 2000 Activities of mitochondrial oxidative phosphorylation enzymes in cultured amniocytes. Clin Chim Acta 298:157-173

25. Schagger H, Cramer WA, von Jagow G 1994 Analysis of molecular masses and oligomeric states of protein complexes by blue native electrophoresis and isolation of membrane protein complexes by two-dimensional native electrophoresis. Anal Biochem 217:220-230

26. Schagger H, von Jagow G 1987 Tricine-sodium dodecyl sulfate-polyacrylamide gel electrophoresis for the separation of proteins in the range from 1 to $100 \mathrm{kDa}$. Anal Biochem 166:368-379

27. Rossignol R, Malgat M, Mazat JP, Letellier T 1999 Threshold effect and tissue specificity. Implication for mitochondrial cytopathies. J Biol Chem 274:33426-33432

28. Rossignol R, Faustin B, Rocher C, Malgat M, Mazat JP, Letellier T 2003 Mitochondrial threshold effects. Biochem J 370:751-762

29. Lenaz G, Bovina C, D'Aurelio M, Fato R, Formiggini G, Genova ML, Giuliano G, Pich MM, Paolucci U, Castelli GP, Ventura B 2002 Role of mitochondria in oxidative stress and aging. Ann N Y Acad Sci 959:199-213

30. Nijtmans LG, Henderson NS, Attardi G, Holt IJ 2001 Impaired ATP synthase assembly associated with a mutation in the human ATP synthase subunit 6 gene. J Biol Chem 276:6755-6762

31. Garcia JJ, Ogilvie I, Robinson BH, Capaldi RA 2000 Structure, functioning, and assembly of the ATP synthase in cells from patients with the T8993G mitochondrial DNA mutation. Comparison with the enzyme in Rho(0) cells completely lacking mtdna. J Biol Chem 275:11075-11081

32. Nijtmans LG, Klement P, Houstek J, van den Bogert C 1995 Assembly of mitochondrial ATP synthase in cultured human cells: implications for mitochondrial diseases. Biochim Biophys Acta 1272:190-198

33. Ackerman SH, Tzagoloff A 1990 Identification of two nuclear genes (ATP11, ATP12) required for assembly of the yeast F1-ATPase. Proc Natl Acad Sci U S A $87: 4986-4990$

34. Lefebvre-Legendre L, Vaillier J, Benabdelhak H, Velours J, Slonimski PP, di Rago JP 2001 Identification of a nuclear gene (FMC1) required for the assembly/stability of yeast mitochondrial F(1)-ATPase in heat stress conditions. J Biol Chem 276:67896796

35. Wang ZG, White PS, Ackerman SH 2001 Atp $11 p$ and Atp12p are assembly factors for the F(1)-AT Pase in human mitochondria. J Biol Chem 276:30773-30778 